\title{
Atmospheric Mining in the Outer Solar System: Resource Capturing, Storage, and Utilization
}

Bryan Palaszewski

Glenn Research Center, Cleveland, Ohio 


\section{NASA STI Program . . . in Profile}

Since its founding, NASA has been dedicated to the advancement of aeronautics and space science. The NASA Scientific and Technical Information (STI) program plays a key part in helping NASA maintain this important role.

The NASA STI Program operates under the auspices of the Agency Chief Information Officer. It collects, organizes, provides for archiving, and disseminates NASA's STI. The NASA STI program provides access to the NASA Aeronautics and Space Database and its public interface, the NASA Technical Reports Server, thus providing one of the largest collections of aeronautical and space science STI in the world. Results are published in both non-NASA channels and by NASA in the NASA STI Report Series, which includes the following report types:

- TECHNICAL PUBLICATION. Reports of completed research or a major significant phase of research that present the results of NASA programs and include extensive data or theoretical analysis. Includes compilations of significant scientific and technical data and information deemed to be of continuing reference value. NASA counterpart of peer-reviewed formal professional papers but has less stringent limitations on manuscript length and extent of graphic presentations.

- TECHNICAL MEMORANDUM. Scientific and technical findings that are preliminary or of specialized interest, e.g., quick release reports, working papers, and bibliographies that contain minimal annotation. Does not contain extensive analysis.

- CONTRACTOR REPORT. Scientific and technical findings by NASA-sponsored contractors and grantees.
- CONFERENCE PUBLICATION. Collected papers from scientific and technical conferences, symposia, seminars, or other meetings sponsored or cosponsored by NASA.

- SPECIAL PUBLICATION. Scientific, technical, or historical information from NASA programs, projects, and missions, often concerned with subjects having substantial public interest.

- TECHNICAL TRANSLATION. Englishlanguage translations of foreign scientific and technical material pertinent to NASA's mission.

Specialized services also include creating custom thesauri, building customized databases, organizing and publishing research results.

For more information about the NASA STI program, see the following:

- Access the NASA STI program home page at http://www.sti.nasa.gov

- E-mail your question to help@sti.nasa.gov

- Fax your question to the NASA STI Information Desk at 443-757-5803

- Phone the NASA STI Information Desk at 443-757-5802

- Write to: STI Information Desk NASA Center for AeroSpace Information 7115 Standard Drive Hanover, MD 21076-1320 
NASA/TM-2014-217892

\section{Atmospheric Mining in the Outer Solar System: Resource Capturing, Storage, and Utilization}

Bryan Palaszewski

Glenn Research Center, Cleveland, Ohio

Prepared for the

48th Joint Propulsion Conference and Exhibit

cosponsored by the AIAA, ASME, SAE, and ASEE

Atlanta, Georgia, July 30-August 1, 2012

National Aeronautics and

Space Administration

Glenn Research Center

Cleveland, Ohio 44135 
Level of Review: This material has been technically reviewed by technical management.

Available from

NASA Center for Aerospace Information 7115 Standard Drive

Hanover, MD 21076-1320
National Technical Information Service 5301 Shawnee Road Alexandria, VA 22312

Available electronically at http://www.sti.nasa.gov 


\title{
Atmospheric Mining in the Outer Solar System: Resource Capturing, Storage, and Utilization
}

\author{
Bryan Palaszewski \\ National Aeronautics and Space Administration \\ Glenn Research Center \\ Cleveland, Ohio 44135
}

\begin{abstract}
Atmospheric mining in the outer solar system has been investigated as a means of fuel production for high energy propulsion and power. Fusion fuels such as helium 3 and hydrogen can be wrested from the atmospheres of Uranus and Neptune and either returned to Earth or used in-situ for energy production. Helium 3 and hydrogen (deuterium, etc.) were the primary gases of interest with hydrogen being the primary propellant for nuclear thermal solid core and gas core rocket-based atmospheric flight. A series of analyses were undertaken to investigate resource capturing aspects of atmospheric mining in the outer solar system. This included the gas capturing rate for hydrogen helium 4 and helium 3 , storage options, and different methods of direct use of the captured gases. Additional supporting analyses were conducted to illuminate vehicle sizing and orbital transportation issues.
\end{abstract}

\section{Nomenclature}

$\begin{array}{ll}\text { 3He } & \text { helium } 3 \\ \text { 4He } & \text { helium (or Helium 4) } \\ \text { AMOSS } & \text { atmospheric mining in the outer solar system } \\ \text { ASC } & \text { aerospacecraft } \\ \text { CC } & \text { closed cycle } \\ \text { delta-V } & \text { change in velocity }(\mathrm{km} / \mathrm{s}) \\ \text { GCR } & \text { gas core rocket } \\ \text { GTOW } & \text { gross takeoff weight } \\ \mathrm{H}_{2} & \text { hydrogen } \\ \mathrm{He} & \text { helium } 4 \\ \text { IEC } & \text { Inertial-Electrostatic Confinement (related to nuclear fusion) } \\ \text { ISRU } & \text { In Situ Resource Utilization } \\ \text { Isp } & \text { specific impulse (s) } \\ \text { K } & \text { Kelvin } \\ \text { kWe } & \text { kilowatts of electric power } \\ \text { LEO } & \text { low Earth orbit } \\ \text { MT } & \text { metric tons } \\ \text { MWe } & \text { megawatt electric (power level) } \\ \text { NEP } & \text { Nuclear Electric Propulsion } \\ \text { NTP } & \text { Nuclear Thermal Propulsion } \\ \text { NTR } & \text { Nuclear Thermal Rocket } \\ \text { OC } & \text { open cycle } \\ \text { O } & \text { oxygen } \\ \text { PPB } & \text { parts per billion } \\ \text { STO } & \text { surface to orbit } \\ \text { UAV } & \text { uninhabited aerial vehicle } \\ & \end{array}$




\subsection{Atmospheric Mining in the Outer Solar System}

Atmospheric mining of the outer solar system is one of the options for creating nuclear fuels, such as helium $3(3 \mathrm{He})$, for future fusion powered exploration vehicles or powering reactors for Earth's planetary energy needs (Refs. 1 to 8). Uranus' and Neptune's atmospheres would be the primary mining sites, and robotic vehicles would wrest these gases from the $\mathrm{H}_{2}-\mathrm{He}$ gases of those planets. While preliminary estimates of the masses of the mining vehicles have been created (Refs. 1 to 7), additional supporting vehicles may enhance the mining scenarios.

There are vast reserves of potential fuels and propellants in the outer planets (Refs. 1 to 7). While the idea of mining outer planet atmospheres is indeed enticing, the challenges to designing mining vehicles may be somewhat daunting. While past studies related to the Daedalus Project (Ref. 7) have assumed the use of fusion propulsion for the aerostat and aerospacecraft (ASC) that mine the atmosphere and carry the fuel to Jupiter's orbit, nuclear thermal rockets may also allow a more near term propulsion option. While the mass of the NTP options will, in most cases, be higher than the fusion powered options, the more near term NTP vehicle may still be attractive (Refs. 8 to 11), although closed cycle gas core nuclear rockets may provide high specific impulse and high thrust without invoking fusion rockets (Refs. 12 to 22).

During the $3 \mathrm{He}$ capturing, large amounts of $\mathrm{H}_{2}$ and $4 \mathrm{He}$ are produced. Analyses were conducted to quantify the mass production rates of these other potential fuels. Also, capturing the $\mathrm{H}_{2}$ and $4 \mathrm{He}$ to fuel additional exploration and exploitation vehicles was addressed. New options for fleets of small and large ASC for exploration and exploitation missions are discussed.

\subsection{Resource Capturing Studies}

Studies of the gas capture rate and its influence on mining time in the atmosphere were conducted. ASC cruisers have been identified as a "best" solution for atmospheric mining (Refs. 1 to 7). To power these vehicles, atmospheric $\mathrm{H}_{2}$ gas would be liquefied and used a rocket propellant for the ascent to orbit. Gaseous or liquid $\mathrm{H}_{2}$ would be used to power the engines during atmospheric mining operations. Figure 1 shows an overall schematic of a closed cycle gas core rocket (GCR) propulsion option. Helium 3 would be separated from the atmospheric $\mathrm{H}_{2}$ and $4 \mathrm{He}$ captured, liquefied and stored as a payload that would be returned to orbit. Table I provides the fraction of $3 \mathrm{He}$ in the outer planet atmospheres.

Figure 2 and Figure 3 show the $3 \mathrm{He}$ mining time versus the atmospheric capture rate for Uranus and Neptune, respectively. A 500-kg payload of $3 \mathrm{He}$ is captured during the mining time.

Figure 4 and Figure 5 provide the sizing of the gas core powered vehicles and a comparison of the solid core and gas core vehicle options, respectively (Ref. 1). The relatively low thrust to weight of the nuclear engines may necessitate the use of a more advanced gas core nuclear engine over the solid core nuclear thermal propulsion (NTP).

\begin{tabular}{l} 
TABLE I.-FRACTION OF 3He AND 4He \\
IN OUTER PLANET ATMOSPHERES \\
\cline { 2 - 3 } \multicolumn{1}{c|}{ Uranus } \\
\begin{tabular}{|l|c|c|}
\hline Amount of 3He in 4He & $1.00 \times 10^{-4}$ & Neptune \\
\hline Amount of 4He in atmosphere & 0.152 & $0.19 \times 10^{-4}$ \\
\hline Amount of 3He in atmosphere & $1.52 \times 10^{-5}$ & $1.90 \times 10^{-5}$ \\
\hline
\end{tabular}
\end{tabular}




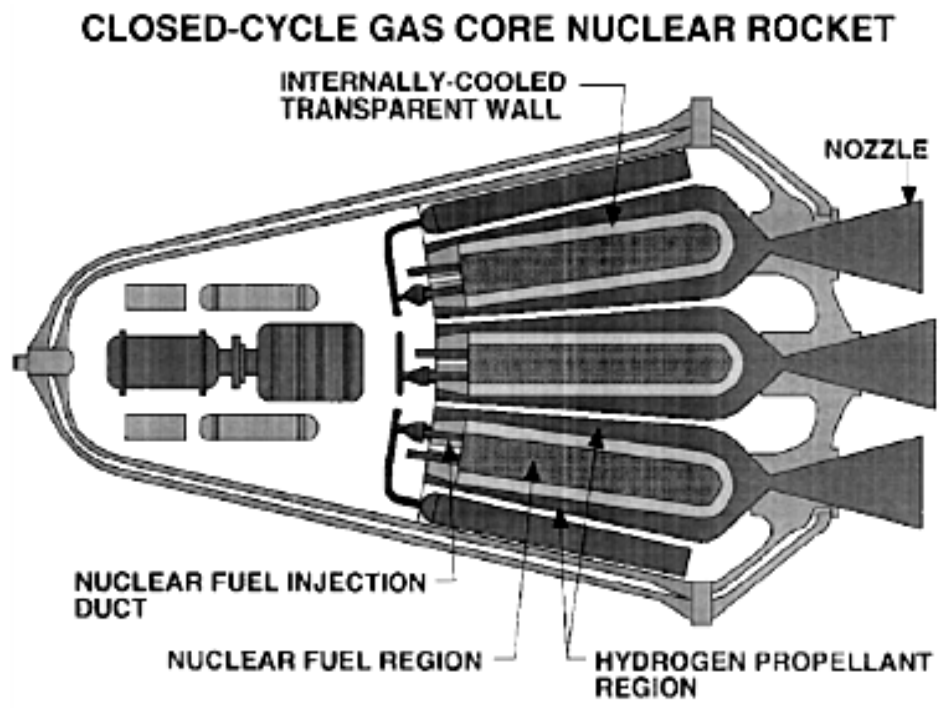

Figure 1.-GCR propulsion for the mining cruiser (Ref. 8). R. Frisbee, "Advanced Space Propulsion for the 21st Century," reprinted by permission of the American Institute for Aeronautics and Astronautics, Inc.

Time needed for capturing $3 \mathrm{He}, 500 \mathrm{~kg}$ of $3 \mathrm{He}$ captured, $3 \mathrm{He}$ concentration $=1.52 \times 10^{\wedge}-5$ in total atmosphere (Uranus)

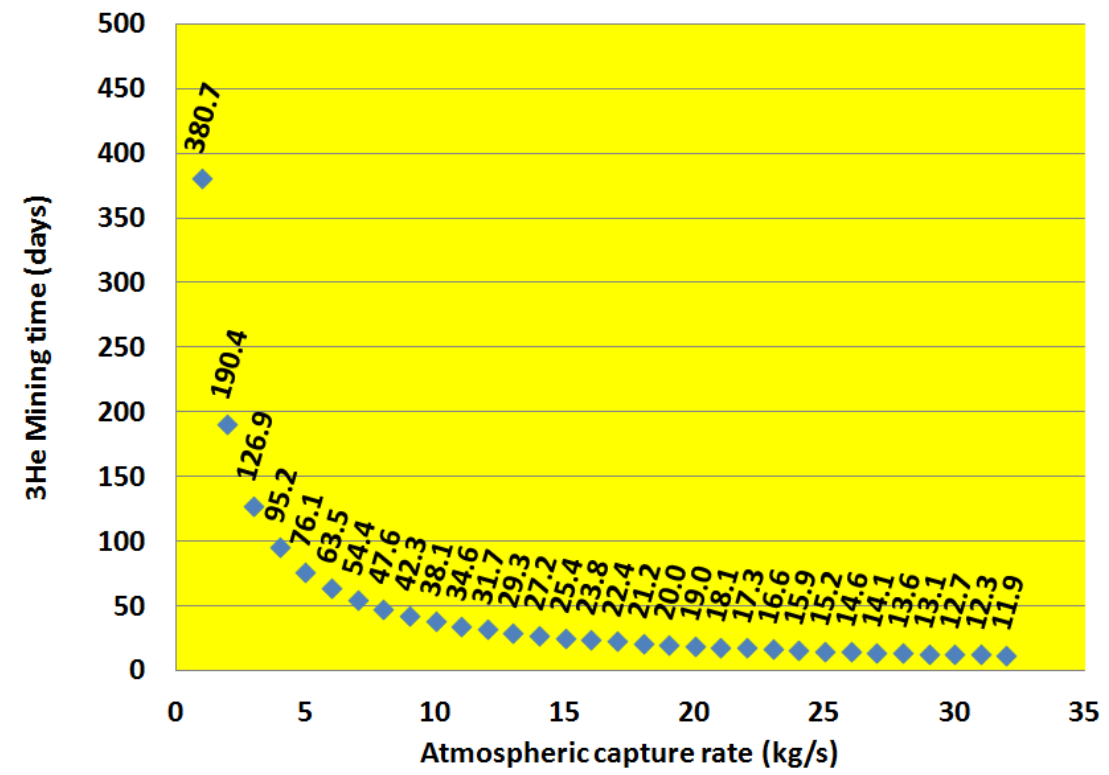

Figure 2.-Mining time versus the capture rate for Uranus. 


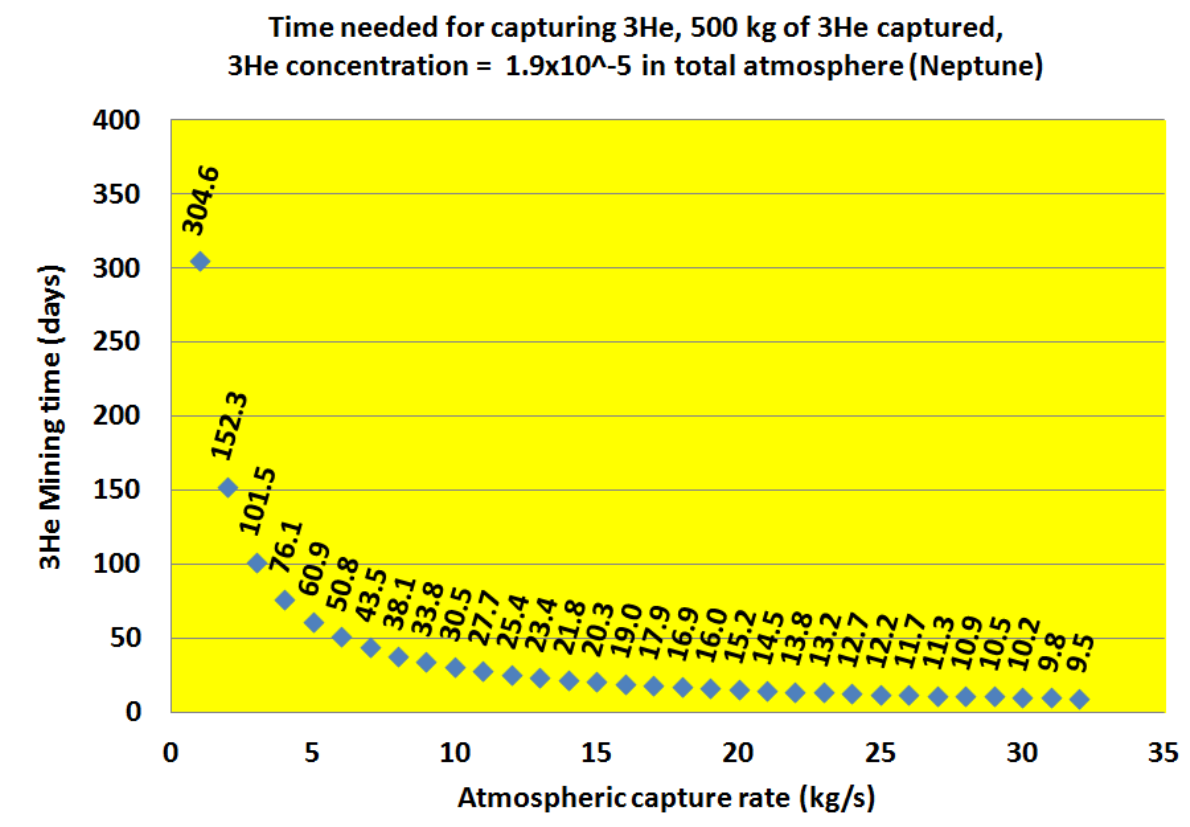

Figure 3.-Mining time versus the capture rate for Neptune.

Nuclear Aerospacecraft, Gas Core, 1,800-s Isp, 20-km/s delta-V capability, 1,000-kg payload

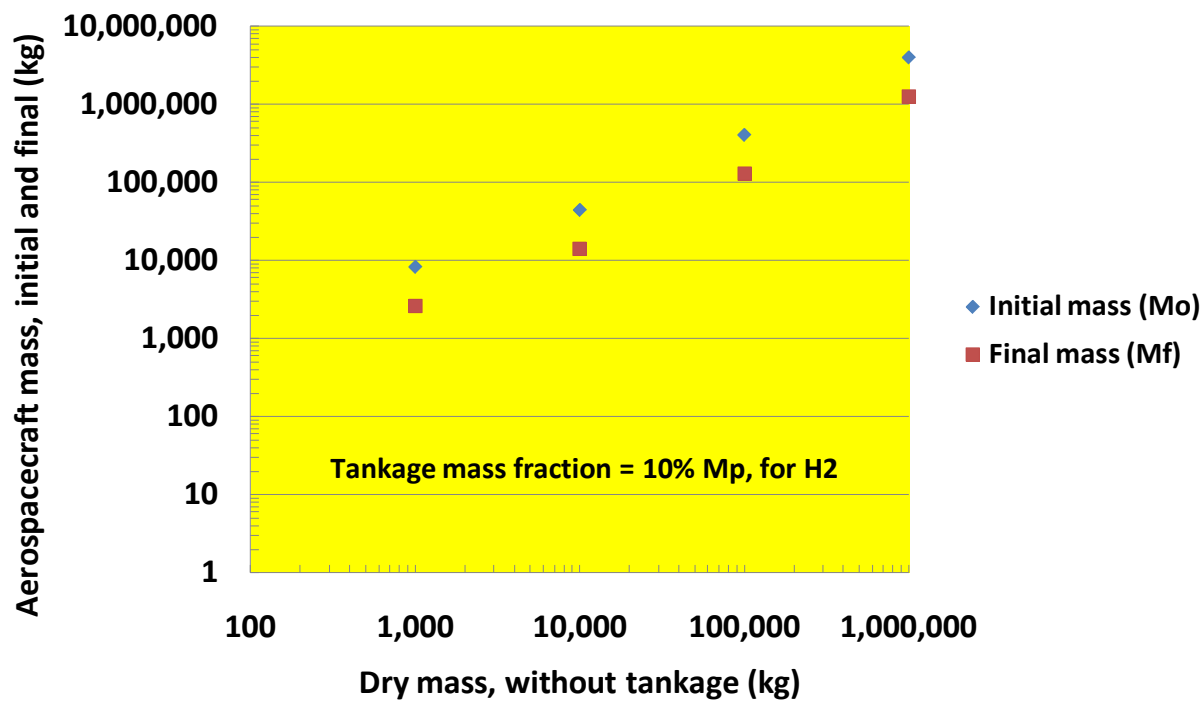

Figure 4.-ASC mass, 1,800-s Isp, Tankage $=10$ percent Mp, representative of gas core nuclear propulsion (Ref. 1). 


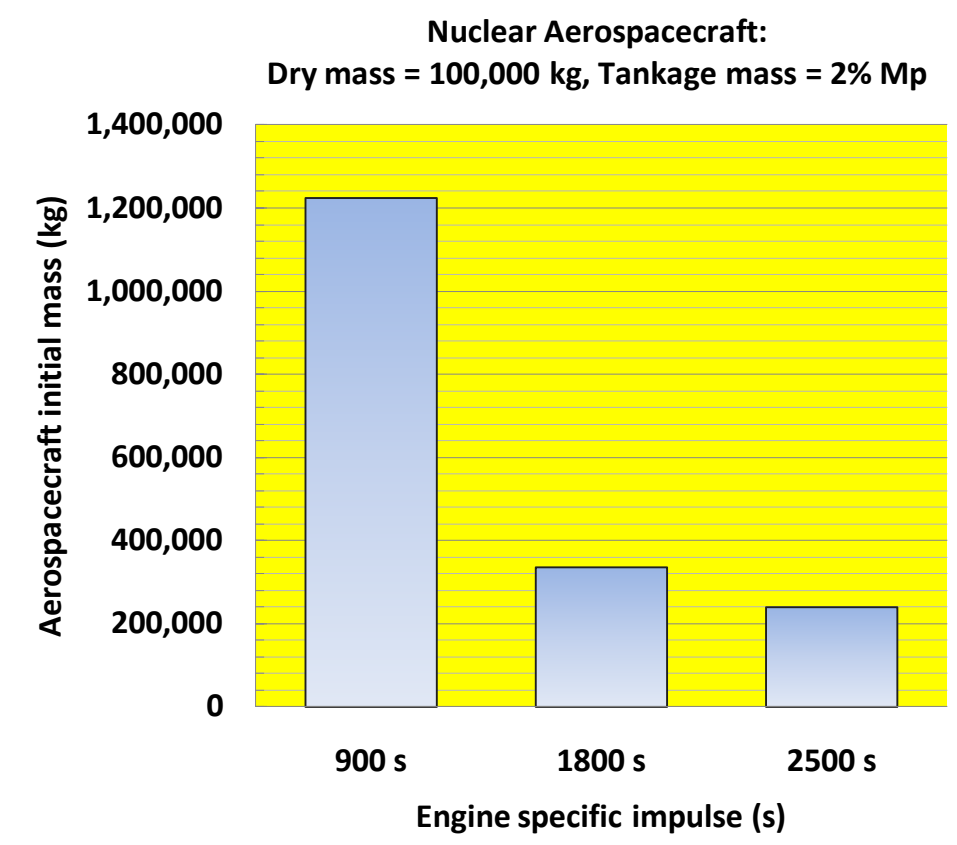

Figure 5.-NTP: solid core and gas core vehicle mass comparison, $100,000 \mathrm{~kg}$ dry mass, 2 percent $\mathrm{H}_{2}$ tankage mass (Ref. 1).

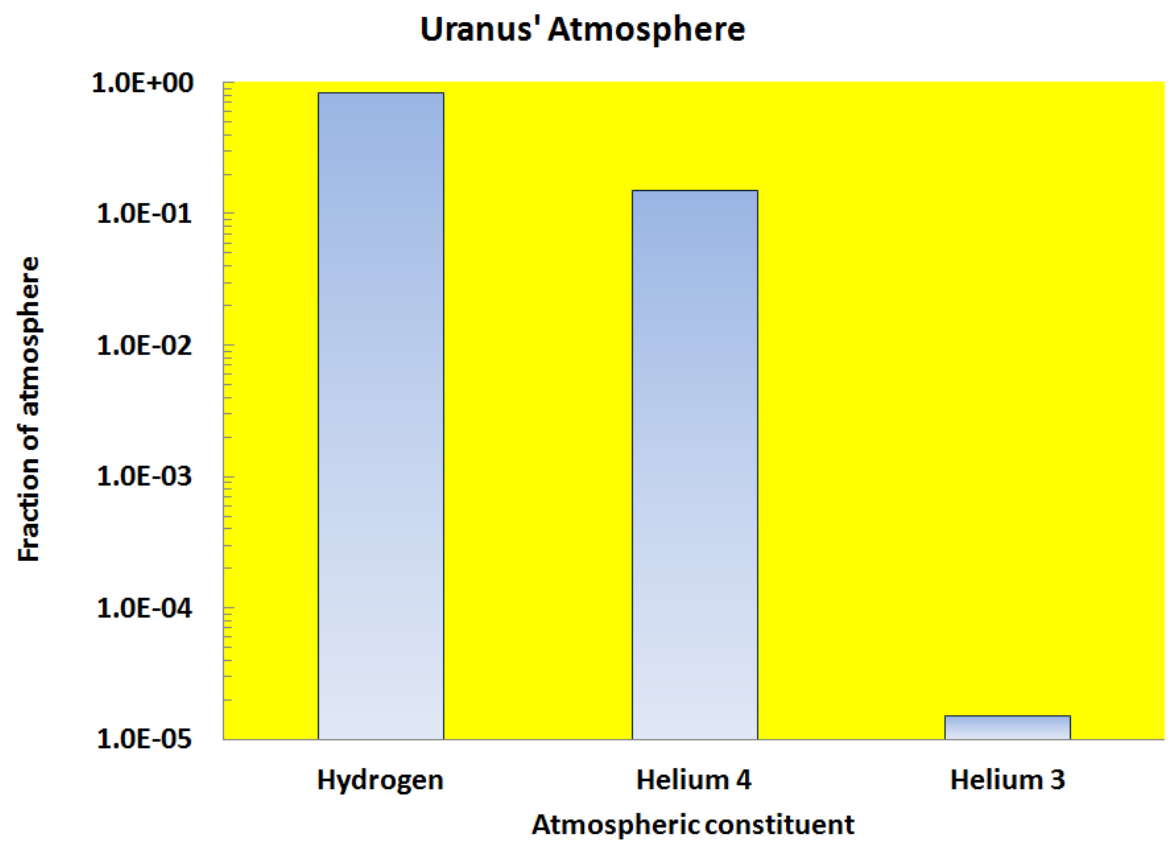

Figure 6.-Fractions of atmospheric gases for Uranus.

\subsection{Fueling and Refueling Options}

After completing the analyses of the time for propellant capture it became clear that a large amount of $\mathrm{LH}_{2}$ was produced each day of $3 \mathrm{He}$ production. Figure 6 and Figure 7 depict the relatively large mass fractions of $\mathrm{H}_{2}$ and $4 \mathrm{He}$ that are processed to extract the desired $3 \mathrm{He}$. It is clear that such large masses will be useful for not only refueling the mining cruiser ASC, but may be important for other related applications. 


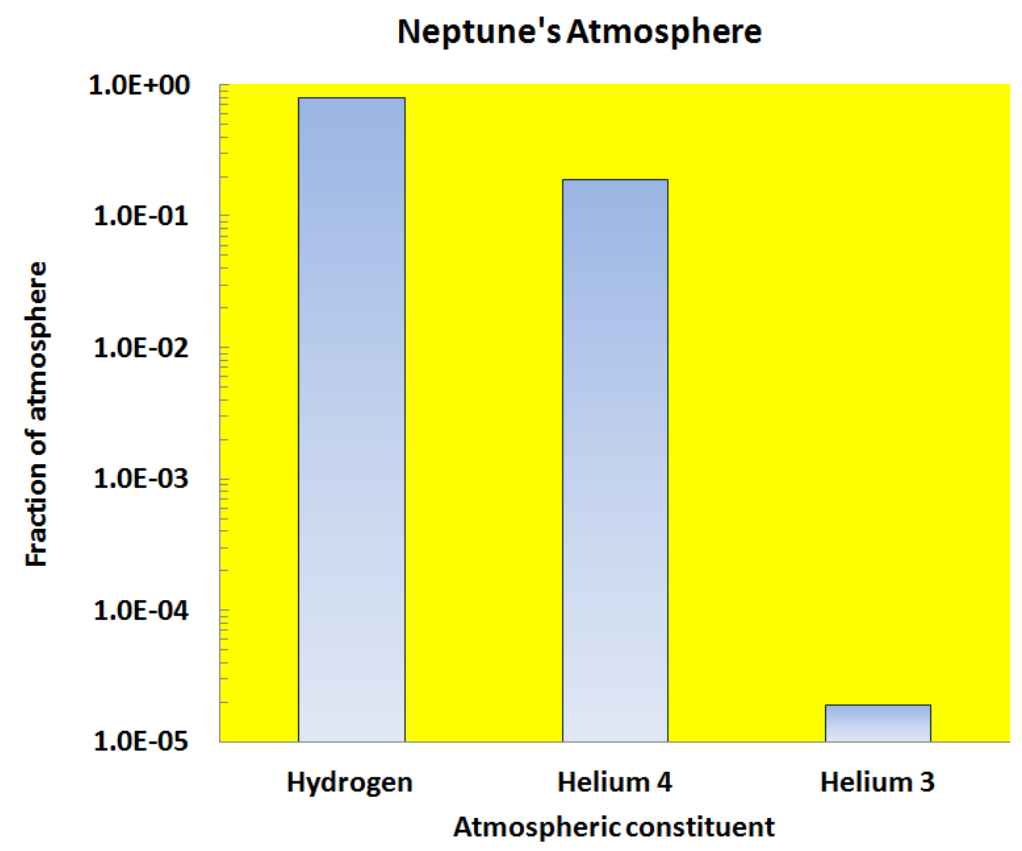

Figure 7.-Fractions of atmospheric gases for Neptune.

Figure 8 shows the $3 \mathrm{He}$ capture time (for $500 \mathrm{~kg}$ ), the mass of $\mathrm{H}_{2}$ produced per day, and the $\mathrm{H}_{2}$ needed to fuel GCR powered ASC at a specific impulse of 1800 and $2500 \mathrm{~s}$, all as a function of atmospheric gas capture rate. In this case, the $3 \mathrm{He}$ in the atmosphere is $=1.52 \times 10^{-5}$ (a case for Uranus), and the ASC dry mass $=100,000 \mathrm{~kg}$. As an example, of the atmospheric capture rate were $4 \mathrm{~kg} / \mathrm{s}$, there required amount of $500 \mathrm{~kg}$ of $3 \mathrm{He}$ would be captured in 95.2 days. During that time, $293,000 \mathrm{~kg}$ of $\mathrm{H}_{2}$ would be produced per day. To fully fuel an 1800 -s Isp gas core ASC is $270,000 \mathrm{~kg}$. A H propellant load of $148,000 \mathrm{~kg}$ is needed for the 2500-s Isp gas core powered ASC. Similarly, if the atmospheric capture rate were $10 \mathrm{~kg} / \mathrm{s}$, the time for capturing the $500 \mathrm{~kg}$ of $3 \mathrm{He}$ would be 38.1 days. During those 38.1 days, $732,600 \mathrm{~kg}$ of $\mathrm{H}_{2}$ would be produced per day. Thus, more than two 1800-s gas core ASC vehicles could be refueled per day. While the mining vehicle (ponderously and politely) continues its $3 \mathrm{He}$ capturing, additional vehicles could flit about far from the mining ASC and gather needed information on potential storms or other disturbances that the mining ASC must avoid.

For a $1,000,000 \mathrm{~kg}$ dry mass, the mining case also show significant $\mathrm{H}_{2}$ benefits. This case is shown in Figure $9 \mathrm{In}$ the case for Neptune $\left(3 \mathrm{He}=1.9 \times 10^{-5}\right)$, at an atmospheric capture rate of $22 \mathrm{~kg} / \mathrm{s}$, there is enough $\mathrm{H}_{2}$ produced to refuel a 2500-s ASC every day. At that capture rate, it takes 13.8 days to mine the required $500 \mathrm{~kg}$ of $3 \mathrm{He}$. So 13 orbital missions could be conducted or numerous sorties in the atmosphere by UAVs requiring smaller $\mathrm{H}_{2}$ propellant loads could be completed.

With this high $\mathrm{H}_{2}$ production rate, fleets of ASC, of a variety of sizes, could be fueled during the nominal time of capturing the $3 \mathrm{He}$. Such a fleet could be atmospheric sampling uninhabited aerial vehicles (UAVs), small orbital missions, or UAVs for in-situ planetary meteorological studies.

Refueling of cryogenic ASC vehicles will no doubt be a challenge (in robotic aerial refueling, etc.), and there will be additional cryogenic transfer losses and propellant tank chilldown requirements, however, the mass of $\mathrm{H}_{2}$ produced is quite impressive and is a ripe area for investigating $\mathrm{H}_{2}$ usage options. 


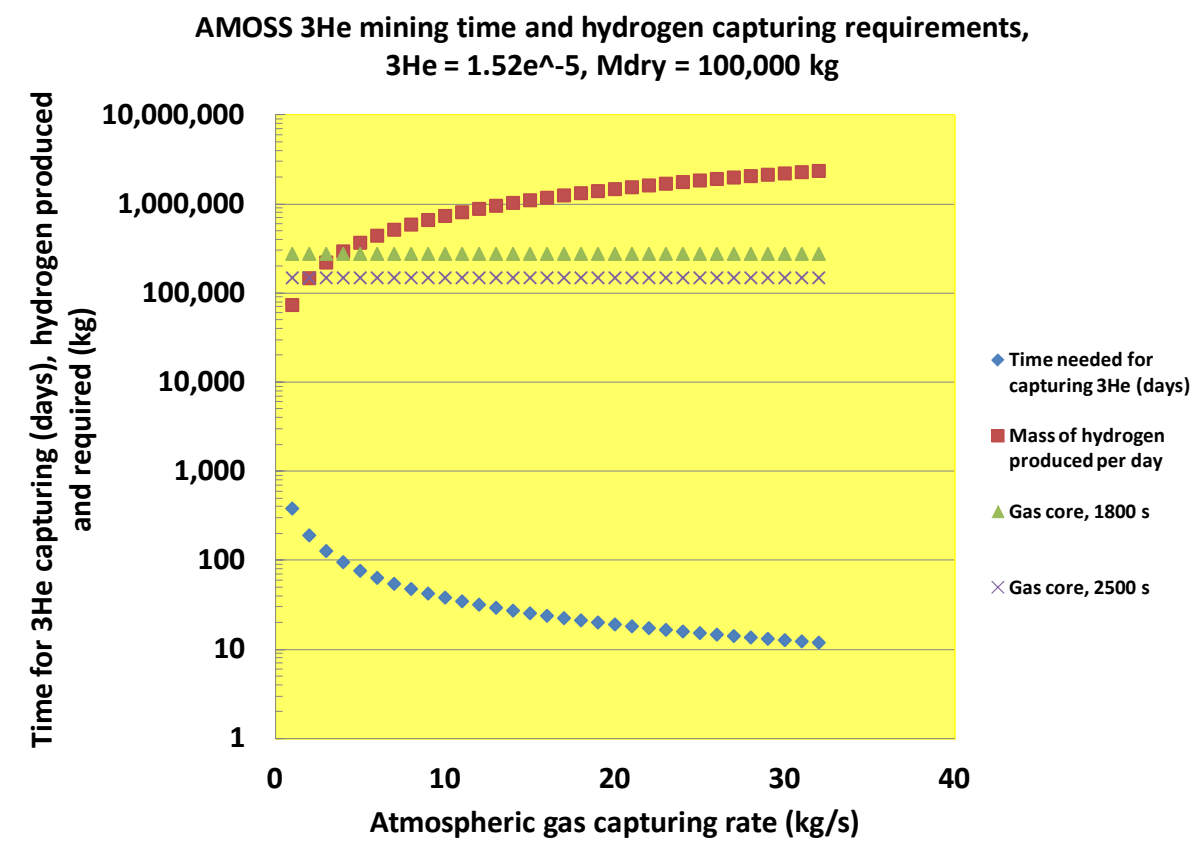

Figure 8.-Helium 3 mining time and $\mathrm{H}_{2}$ capture (mass per day) versus atmospheric gas capture rate for Uranus.

AMOSS $3 \mathrm{He}$ mining time and hydrogen capturing requirements,

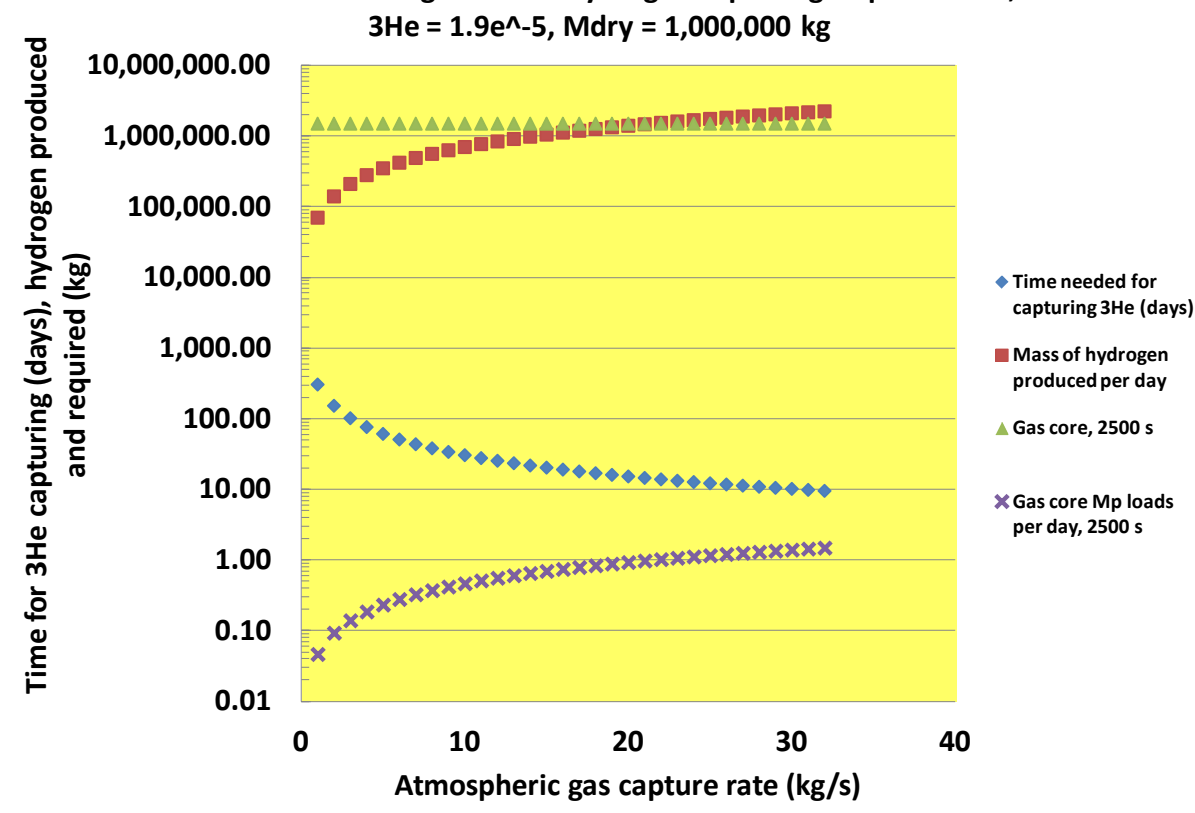

Figure 9.-Helium 3 mining time and $\mathrm{H}_{2}$ capture (mass per day) versus atmospheric gas capture rate for Neptune. 


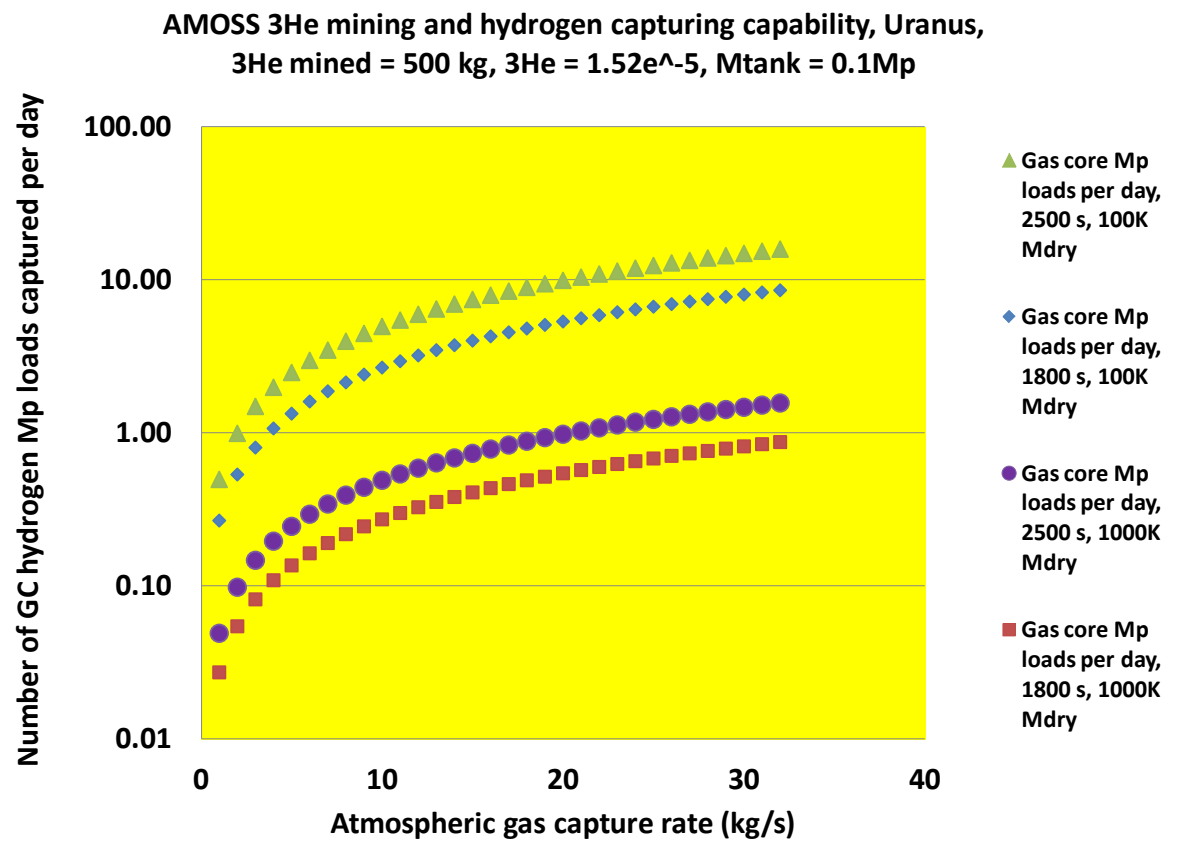

Figure 10.-Number of GCR $\mathrm{H}_{2}$ propellant loads captured per day versus atmospheric gas capture rate-Uranus.

Figure 10 compares all of the $\mathrm{H}_{2}$ capturing cases for Uranus. In the chart, the number of $\mathrm{GCR} \mathrm{H}_{2}$ propellant loads captured is as high at 15.8 for the 2500 -s GCR cases (with a 100,000 kg dry mass, 32 $\mathrm{kg} / \mathrm{s}$ capture rate). At a $10 \mathrm{~kg} / \mathrm{s}$ atmospheric capture rate, the maximum number of $\mathrm{H}_{2}$ loads is 4.95 (or just less than 5). The lowest value is $0.27 \mathrm{H}_{2}$ loads per day. Similar analyses are shown for the other vehicle designs for Neptune in Figure 11: 1800 and 2500 s Isp nuclear GCR (SC with 100 and 1000 MT dry masses. With the Neptune analysis, the rates of $\mathrm{H}_{2}$ capture are slightly lower, and the capture rates are very similar to the Uranus cases.

While capturing $3 \mathrm{He}$ and $\mathrm{H}_{2}$, there is also a very significant amount of $4 \mathrm{He}$ than can be captured. Figure 12 and Figure 13 provide the $4 \mathrm{He}$ capture capability per day. The capture capability of the $4 \mathrm{He}$ is expressed in the equivalent masses of $\mathrm{H}_{2}$ to fuel the GCRs. This equivalent figure of merit of GCR propellant loads makes for a more direct comparison of the masses of $\mathrm{H}_{2}$ and $4 \mathrm{He}$. The $4 \mathrm{He}$ capture masses are approximately 15 to 19 percent of the $\mathrm{H}_{2}$ capture masses. With this added $4 \mathrm{He}$ resource, many vehicles could be fueled. Entire fleets of ASC or other aerial vehicles (UAVs, balloons, rockets, etc.) could fly through the outer planet atmospheres, for global weather observations, localized storm or other disturbance investigations, wind speed measurements, polar observations, etc. Deep-diving aircraft (built with the strength to withstand many atmospheres of pressure) powered by the $4 \mathrm{He}$ may be designed to probe the higher density regions of the gas giants. 
AMOSS $3 \mathrm{He}$ mining and hydrogen capturing capability, Neptune, $3 \mathrm{He}$ mined $=500 \mathrm{~kg}, 3 \mathrm{He}=1.9 \mathrm{e}^{\wedge}-5, \mathrm{M}$ tank $=0.1 \mathrm{Mp}$

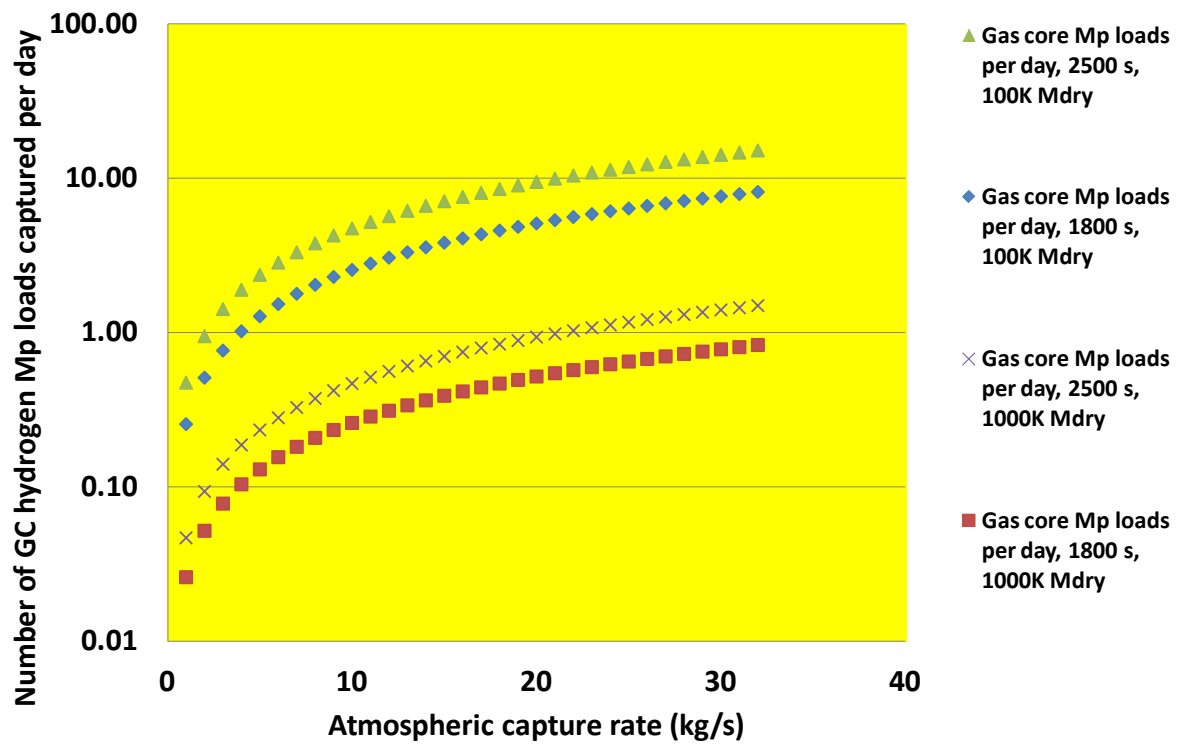

Figure 11.-Number of GCR $\mathrm{H}_{2}$ propellant loads captured per day versus atmospheric gas capture rate-Neptune.

AMOSS $3 \mathrm{He}$ mining and helium capturing capability, Uranus, $3 \mathrm{He}$ mined $=500 \mathrm{~kg}, 3 \mathrm{He}=1.52 \mathrm{e}^{\wedge}-5, \mathrm{Mtank}=0.1 \mathrm{Mp}$

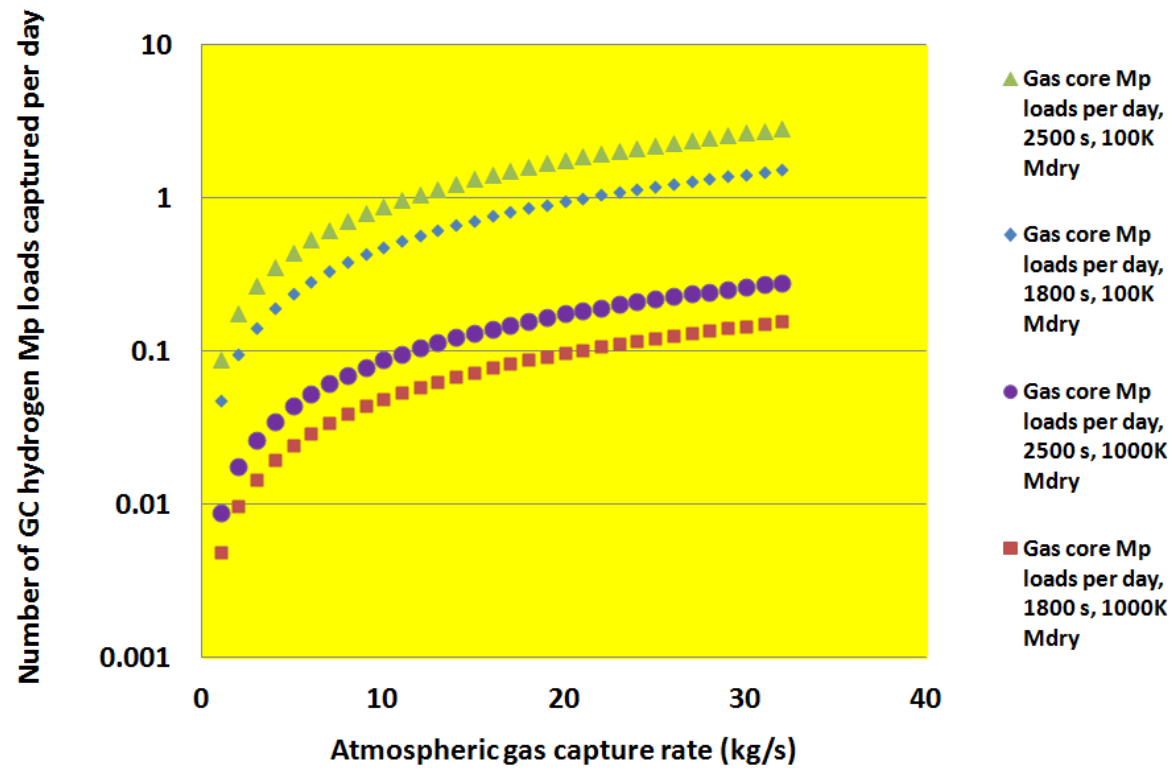

Figure 12.-Number of GCR (mass equivalent $\mathrm{H}_{2}$ ) propellant loads of $4 \mathrm{He}$ captured per day versus atmospheric gas capture rate-Uranus. 


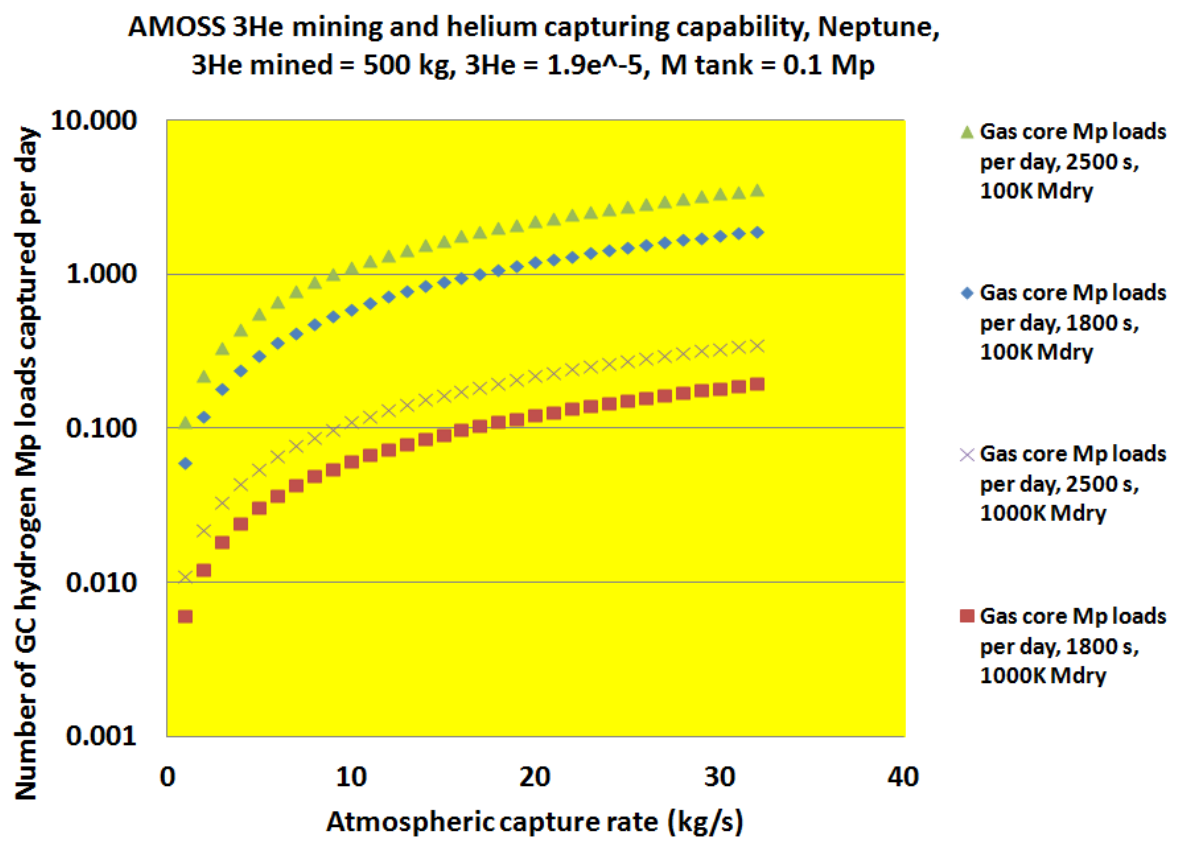

Figure 13.-Number of GCR (mass equivalent $\mathrm{H}_{2}$ ) propellant loads of $4 \mathrm{He}$ captured per day versus atmospheric gas capture rate-Neptune

\subsection{Supporting Analyses and Observations}

In addition to the capturing studies, reviews of outer planet spacecraft design issues were initiated. A list of the issues to be addressed is noted below:

- Mission planning.

- Cryogenic fuel storage issues.

- Cryogenic dust (outer planet moons, ice migration). Mass concentrations (mascons) on the moons, etc.

- Drilling into ice, walkers on ice-dust surfaces.

- Possible power generation using electrodynamic tethers (EDT), cutting across the outer planet magnetic field lines.

- Global Positioning System (GPS) vehicles in outer planet orbits for navigation.

- Observational satellite for outer planet weather monitoring, diverting cruisers from harm.

Figure A.1 to Figure A.4 also illuminate some of the issues to be analyzed.

\subsection{Concluding Remarks}

Atmospheric mining in the outer solar system can be a powerful tool for extracting fuels from the outer planets and allowing fast human and robotic exploration of the solar system. Preliminary designs of ASC with GCR nuclear engines for mining the outer planets were developed (Ref. 1). Analyses showed that gas core engines can reduce the mass of such ASC mining vehicles very significantly: from 72 to 80 percent reduction over NTP solid core powered ASC mining vehicles. While this mass reduction is important in reducing the mass of the overall mining system, the complexity of a fissioning plasma GCR is much higher than the more traditional solid core NTP engines. Additional analyses were conducted to calculate the capture rates of $\mathrm{H}_{2}$ and $4 \mathrm{He}$ during the mining process. Very large masses of $\mathrm{H}_{2}$ and $4 \mathrm{He}$ are produced every day during the often lengthy process of $3 \mathrm{He}$ capture and gas separation. Typically, these 
very large additional fuel masses can dwarf the requirements needed for $\mathrm{H}_{2}$ capture for ascent to orbit. Thus, the potential for fueling small and large fleets of additional exploration and exploitation vehicles exists. Additional ASC or other aerial vehicles (UAVs, balloons, rockets, etc.) could fly through the outer planet atmospheres, for global weather observations, localized storm or other disturbance investigations, wind speed measurements, polar observations, etc. Deep-diving aircraft (built with the strength to withstand many atmospheres of pressure) powered by the excess $\mathrm{H}_{2}$ or $4 \mathrm{He}$ may be designed to probe the higher density regions of the gas giants.

Based on these analyses, there will likely be several possible future avenues for effective use the gases of the outer planets for exciting exploration missions. When focusing on Uranus and Neptune, these planets offer vast reservoirs of fuels that are more readily accessible than those from Jupiter and Saturn and, with the advent of nuclear fusion propulsion, may offer us the best option for the first practical interstellar flight. 



\section{Appendix A.--Issues for Cryogenic Operations}

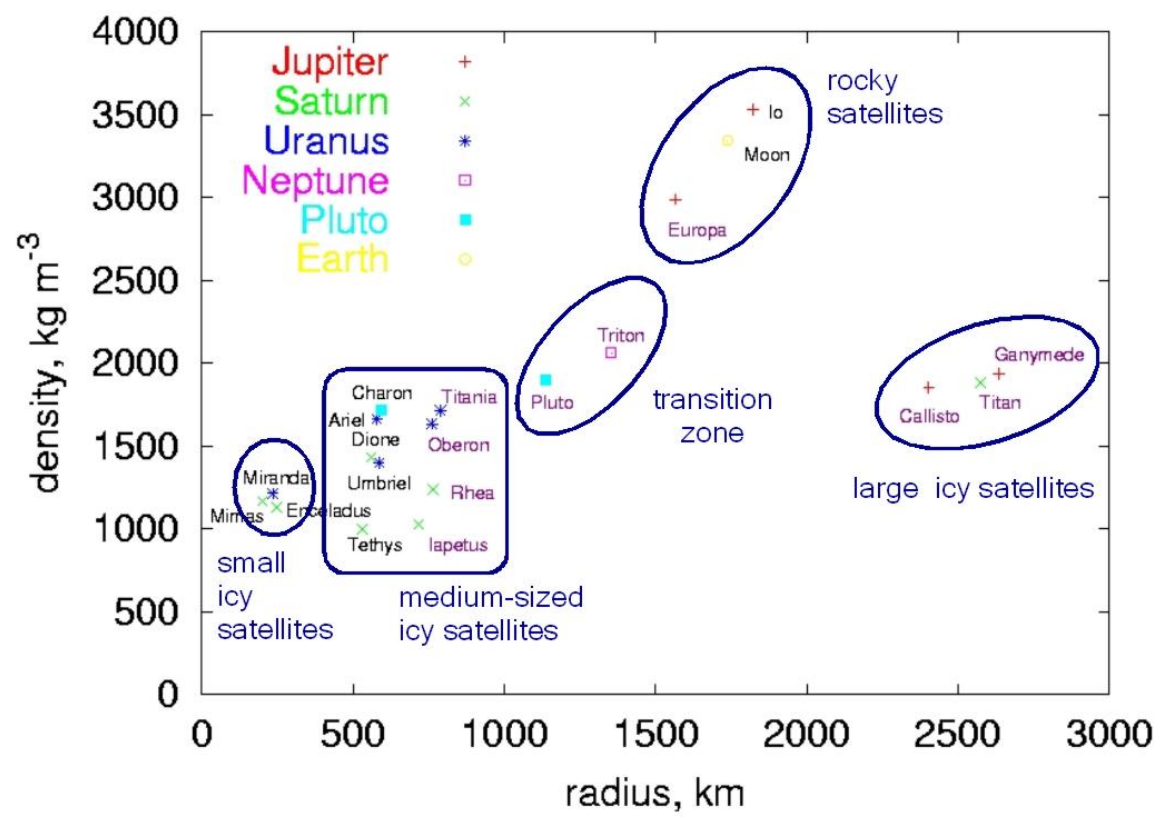

Figure A.1.-Outer planet moon densities ${ }^{1}$ (Ref. 20).

\section{Moon Bases in Cryogenic Environments: Issues}

- Power sources

- Seals

- Rotating components

- Adhesives

- Flexible - inflatable surfaces

- Dust, ice characteristics

- Robots, for maintenance, etc.

- Warmth for, maintenance of astronauts

Figure A.2.--Issues for cryogenic outer planet moon surface operations (RASC, HOPE study, Refs. 21 and 22).

\footnotetext{
${ }^{1}$ Reprinted from Icarus, Volume 185, Issue 1: Hussmann, Hauke; Sohl, Frank; Spohn, Tilman: "Subsurface oceans and deep interiors of medium-sized outer planet satellites and large trans-Neptunian objects," pp. 258-273, Copyright 2006, with permission from Elsevier.
} 


\section{Atmosphere of Uranus: \\ K.A. Rages, H.B. Hammel, A.J. Friedson, Evidence for temporal change at Uranus' south pole, 2004}

- Flight in the outer planet atmospheres are based on flight at altitudes where the atmospheric pressure is about 1 atmosphere.

- The charts notes that this altitude implies flying in the haze layer of Uranus.

- The issue of flight in the haze layer should be investigated (effects on aerospacecraft, mining efficiency, etc.).

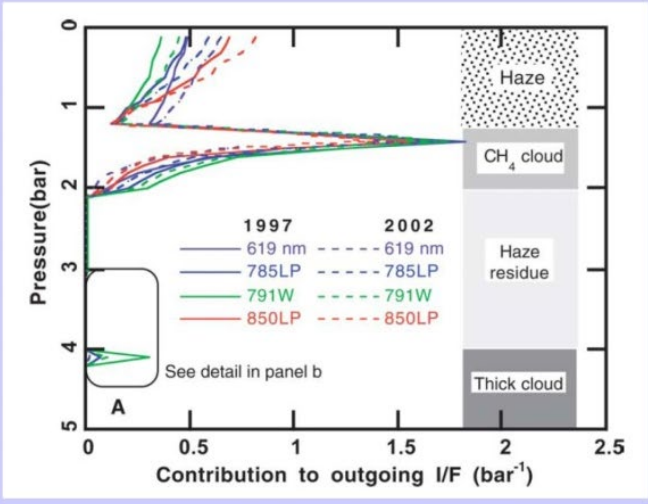

Figure A.3.-Uranus atmospheric structure, haze phenomena ${ }^{2}$ (Ref. 23).

\section{AMOSS: What's Next?}

- Daedalus Redux (British Interplanetary Society (BIS) Study, Martin, A., et al., 1979).

- More attention to atmospheric mining for starship fueling.

- Schedules of ISRU fuel deliveries.

- Effect on construction - if ISRU process slowed or speeded up?

- Daedalus study assumed fusion powered atmospheric transfer vehicles and aerostats for gathering helium 3 and deuterium from Jupiter's atmosphere.

- Move mining location to Uranus or Neptune.

- Recent studies of AMOSS (Palaszewski, et al. AIAA JPC 2005, 2006, 2007, 2008) have used nuclear thermal propulsion (NTP) aerospacecraft (cruiser aircraft) for fuel mining and orbital delivery.

- Is NTP effective as a propulsion option? Is fusion required?

- Development of micro-factories (or macro-factories, or nanofactories(?)) for ship assembly and non-fuel related construction.

- Time added for nano- or micro-factory versus macro-factory construction (time for assembling atoms and molecules, literally...)

Figure A.4.-Atmospheric mining issues.

\section{References}

1. Palaszewski, B., "Atmospheric Mining in the Outer Solar System: Issues and Challenges for Mining Vehicle Propulsion,” AIAA 2011-6041, August 2011.

2. Palaszewski, B., "Atmospheric Mining in the Outer Solar System: University Studies of Mining Vehicles and Propulsion," AIAA 2010-6573, August 2010.

\footnotetext{
${ }^{2}$ Reprinted from Icarus, Volume 172, Issue 2: K.A. Rages, H.B. Hammel, A.J. Friedsond: "Evidence for temporal change at Uranus' south pole," pp. 548-554, Copyright 2004, with permission from Elsevier.
} 
3. Palaszewski, B., "Atmospheric Mining in the Outer Solar System: Mining Design Issues and Considerations," AIAA 2009-4961, August 2009.

4. Palaszewski, B., "Atmospheric Mining in the Outer Solar System: Orbital Transfer Vehicles and Outer Planet Moon Base Options,” AIAA 2008-4861, July 2008.

5. Palaszewski, B., "Atmospheric Mining In The Outer Solar System: Mission Scenarios and Options For In-Situ Resource Utilization.” AIAA 2007-5598, July 2007.

6. Palaszewski, B., "Atmospheric Mining in The Outer Solar System: Vehicle Sizing Issues." AIAA 2006-5222, July 2006.

7. Palaszewski, B., "Atmospheric Mining in the Outer Solar System," AIAA 2005-4319, July 2005.

8. Frisbee, R., "Advanced Space Propulsion for the 21st Century," Journal of Propulsion and Power, Vol. 19, No. 6, Nov-Dec 2003.

9. Dunn, Bruce P., "High-Energy Orbit Refueling for Orbital Transfer Vehicles," Journal of Spacecraft and Rockets Volume. 24, No. 6, 1987, pp. 518-522.

10. Noca, M.; Polk, J. E. "Ion Thrusters and LFAs For Outer Planet Exploration,” AAAF 6th International Symposium; Versailles; France, May 2002.

11. Hunt, James L., Laruelle, Gerard, Wagner, Alain, "Systems Challenges for Hypersonic Vehicles;" AGARD Interpanel Symposium on Future Aerospace Technology in Service to the Alliance, NASATM-112908, AGARD-Paper-C37, 1997.

12. Starr, Brett R.; Westhelle, Carlos H.; Masciarelli, James P., "Aerocapture Performance Analysis For A Neptune-Triton Exploration Mission," NASA/TM-2006-214300, April 2006.

13. Bussard, R., "ASPEN II: Two Staging and Radiation Shielding Effects on ASPEN Vehicle Performance," LA-26-80, 09/06/1967 and in "ASPEN: Nuclear Propulsion for Earth to Orbit Aerospace Plane Vehicles," Robert W. Bussard, Proceedings International Conference on Spaceflight, Rome. June 1971.

14. Bussard, R., and Jameson, L.W.; "The QED Engine Spectrum: Fusion Electric Propulsion for Airbreathing to Interstellar Flight," AIAA paper 93-2006, 29th Joint Propulsion Conference, Monterey, CA 6/28 to 6/30/1993; in JPP, Volume 11, Number 2, pp 365/372.

15. Borowski, Stanley K.; Dudzinski, Leonard A.; and McGuire, Melissa L.: "Artificial Gravity Vehicle Design Option for NASA's Human Mars Mission Using "Bimodal” NTR Propulsion," AIAA Paper 99-2545, 1999.

16. Kendall, J. S.; Stoeffler, R. C., "Conceptual design studies and experiments related to cavity exhaust systems for nuclear light bulb configurations," Report Number: L-910900-15; NASA-CR-129298

17. Latham, T. S.; Rodgers, R. J., "Small nuclear light bulb engines with cold beryllium reflectors," Report Number: AIAA Paper 72-1093.

18. Latham, T. S., "Summary of the performance characteristics of the nuclear light bulb engine," Report Number: AIAA Paper 71-642.

19. Rodgers, R. J.; Latham, T. S., "Analytical design and performance studies of the nuclear light bulb engine," Report Number: L-910900-16; NASA-CR-129295.

20. Hussmann, Hauke; Sohl, Frank; Spohn, Tilman: "Subsurface oceans and deep interiors of mediumsized outer planet satellites and large trans-Neptunian objects," Icarus, Vol. 185, Issue 1: pp. 258273.

21. Troutman, Patrick A., Kristen Bethke, Fred Stillwagen, Darrell L. Caldwell, Jr., Ram Manvi, Chris Strickland, Shawn A. Krizan, "Revolutionary Concepts for Human Outer Planet Exploration (HOPE)," Space Technology \& Applications International Forum (STAIF - 2003), February 2-6, 2003, Albuquerque, New Mexico.

22. R.B. Adams, R.A. Alexander, J.M. Chapman, S.S. Fincher, R.C. Hopkins, A.D. Philips, T.T. Polsgrove, R.J. Litchford, and B.W. Patton, G. Statham and P.S. White, Y.C.F. Thio, "Conceptual Design of In-Space Vehicles for Human Exploration of the Outer Planets," NASA/TP-2003212691, November 2003.

23. Rages, K.A., Hammel, H.B., and Friedsond, A.J., "Evidence for temporal change at Uranus' south pole,” Icarus 172 (2004) pp. 548-554). 


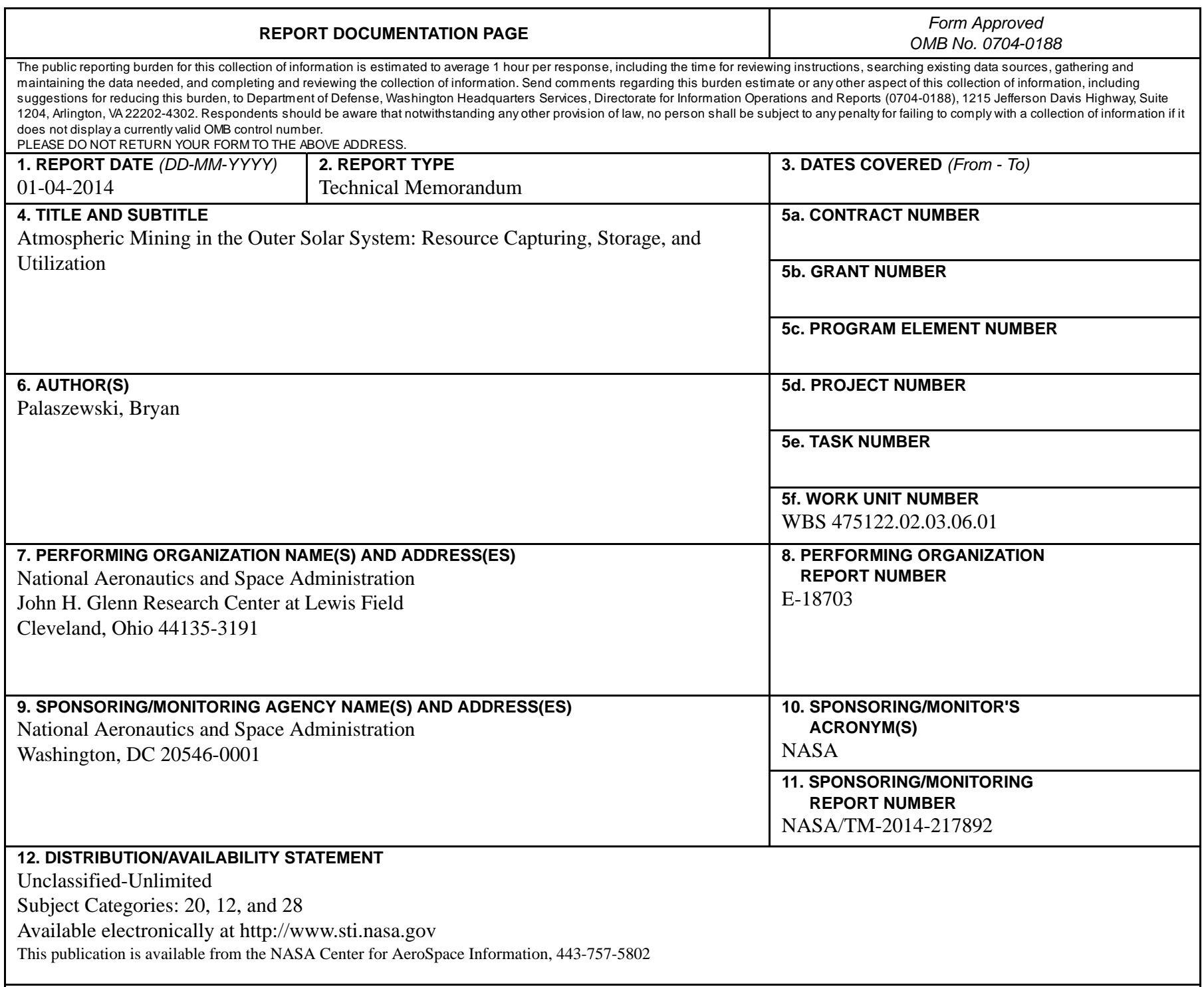

\section{SUPPLEMENTARY NOTES}

\section{ABSTRACT}

Atmospheric mining in the outer solar system has been investigated as a means of fuel production for high energy propulsion and power. Fusion fuels such as helium 3 and hydrogen can be wrested from the atmospheres of Uranus and Neptune and either returned to Earth or used in-situ for energy production. Helium 3 and hydrogen (deuterium, etc.) were the primary gases of interest with hydrogen being the primary propellant for nuclear thermal solid core and gas core rocket-based atmospheric flight. A series of analyses were undertaken to investigate resource capturing aspects of atmospheric mining in the outer solar system. This included the gas capturing rate for hydrogen helium 4 and helium 3, storage options, and different methods of direct use of the captured gases. Additional supporting analyses were conducted to illuminate vehicle sizing and orbital transportation issues.

\section{SUBJECT TERMS}

Propulsion; Nuclear systems; Atmospheric mining; Power systems; In situ resource utilization; Outer planet exploration

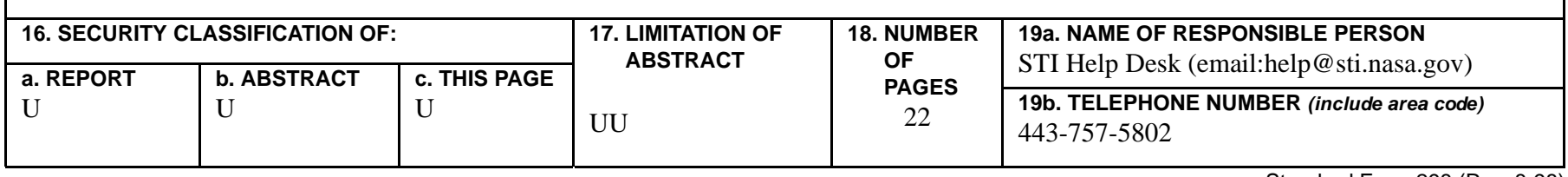



